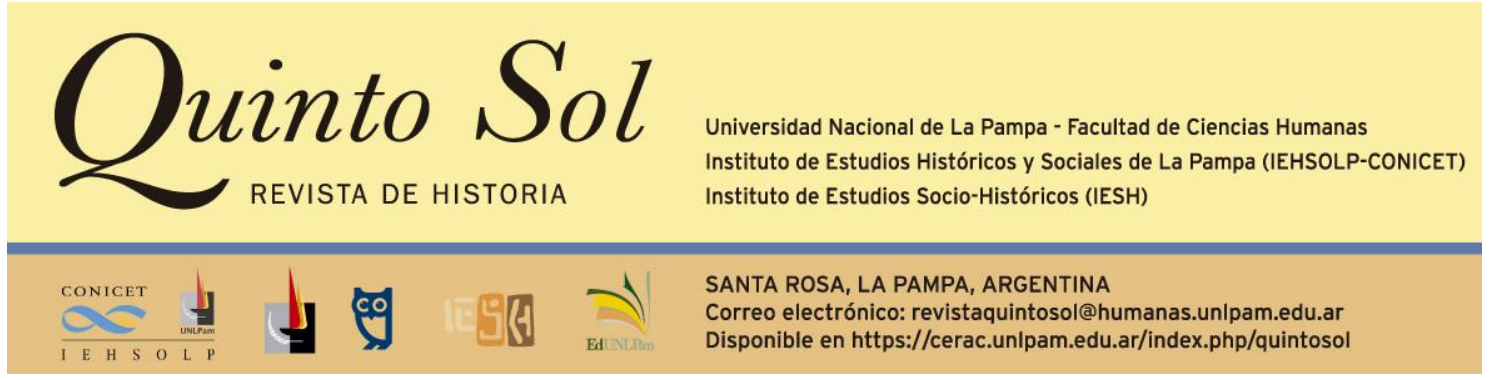

Quinto Sol, vol. 25, n², mayo-agosto, ISSN 1851-2879, pp. 1-4

http://dx.doi.org/10.19137/qs.v25i2.5615

Esta obra se publica bajo licencia Creative Commons 4.0 Internacional. (Atribución-No ComercialCompartir Igual)

\title{
Daniele Menozzi. Iglesia y derechos humanos. Ley natural y modernidad política, de la Revolución francesa hasta nuestros días. Prensas de la Universidad de Zaragoza, 2019, 302 páginas.
}

\section{Eric Morales Schmuker}

Universidad Nacional de La Pampa. Facultad de Ciencias Humanas. Instituto de Estudios Históricos y Sociales de La Pampa. Instituto de Estudios Socio-Históricos

Argentina

Correo electrónico: eric.morales.schmuker@outlook.com

En la segunda Audiencia General de agosto de 2020, el papa Francisco sostuvo que el coronavirus no era la única enfermedad que debía ser combatida. Para el Obispo de Roma, la pandemia visibilizó otras patologías de base, como "la visión distorsionada de la persona", "que ignora su dignidad y su carácter relacional". En este sentido, recordó que "la dignidad humana es inalienable, porque ha sido creada a imagen de Dios", y apeló a la Declaración Universal de los Derechos Humanos como la referencia más cercana a ese principio. ${ }^{1}$ Tal conceptualización había sido expuesta dos años atrás en la Conferencia Internacional "Los derechos humanos en el mundo contemporáneo: conquistas, omisiones, negaciones", organizada por la Pontificia Universidad Gregoriana de Roma (Italia). En ocasión del septuagésimo aniversario de la Carta de 1948, el Sumo Pontífice sostuvo que la Declaración de la Asamblea de las Naciones Unidas reconoció "la igual dignidad de toda persona humana", de las cuales derivan

\footnotetext{
${ }^{1}$ Papa Francisco: la dignidad humana como fundamento de toda la vida social (12 de agosto de 2020). Vatican news. https://www.vaticannews.va/es/papa/news/2020-08/catequesis-papafrancisco-audiencia-general-12-agosto-2020.html
} 
derechos fundamentales, "enraizados en su naturaleza" (es decir, en la "unidad inseparable de cuerpo y alma"), y deberes para con la comunidad. ${ }^{2}$

Ahora bien, ¿cuál es la interpretación que la Iglesia de Roma ha realizado sobre los derechos humanos? ¿Qué alcance ha tenido el documento adoptado por las Naciones Unidas en 1948 dentro del mundo católico? ¿Cuán restrictivo o novedoso es el pronunciamiento de Jorge Bergoglio? En Iglesia y derechos humanos. Ley natural y modernidad política, de la Revolución francesa hasta nuestros días, Daniele Menozzi nos brinda herramientas para ensayar algunas respuestas y formular otros interrogantes sobre estas cuestiones.

El volumen, publicado en español por Prensas de la Universidad de Zaragoza -la versión italiana fue editada por il Mulino en 2012-, comprende la posición de la Iglesia católica frente a los derechos humanos desde la promulgación de la Carta de 1789 hasta el pontificado de Joseph Ratzinger. La temática puede no resultar novedosa. Sin embargo, las investigaciones orientadas a la historia de la postura mantenida por la institución eclesiástica en esta materia son escasas, más aún si se considera la relevancia de un binomio que ha encontrado un lugar destacado en la agenda pública a ambos lados del océano Atlántico.

En las últimas décadas, tal como señala el estudioso europeo, el lugar asumido por la Iglesia católica en la tutela y el respeto efectivo de los derechos humanos le ha garantizado una presencia destacada en el concierto internacional, si bien encontró una recepción dividida al interior de las sociedades democráticas. Hay quienes insisten en el fuerte compromiso de Roma en la denuncia de la violación de los derechos humanos y la recomendación de su adecuada aplicación, particularmente en el marco de catástrofes y conflictos armados. En cambio, otros sectores, varios de ellos incluidos en el arco político progresista, mantienen una fuerte crítica al discurso de la autoridad eclesiástica, entendido como atemporal y limitado en materia de género, familia, salud reproductiva, genética.

Frente a este panorama, Menozzi propone pensar el vínculo entre religión y derechos humanos desde una doble perspectiva, de largo plazo y transnacional, atendiendo a las múltiples aristas de una construcción histórica compleja. Se trata de un terreno bastante conocido para el licenciado en Ciencia Política por la Universidad de Bolonia, profesor de Historia Contemporánea en la Scuola Normale Superiore de Pisa y autor de varias obras sobre las relaciones entre catolicismo y sociedad desde el siglo XVIII, entre ellos, Da Cristo Re alla città degli uomini. Cattolicesimo e politica nel '900 (2019) y "Crociata". Storia di un'ideologia dalla Rivoluzione francese a Bergoglio (2020).

De acuerdo con Menozzi, el problema debe ser formulado dentro de las coordenadas temporales adecuadas. Un abordaje acotado a la segunda mitad del siglo XX, a la etapa abierta con la encíclica Pacem in terris (1963) de Juan XXIII y el reconocimiento de la Declaración Universal de los Derechos Humanos promulgada por las Naciones Unidas, conlleva la clausura de un largo período de oposición de Roma. Además, impide observar los condicionamientos, avances y límites en el proceso de entendimiento e incorporación de una tradición política y cultural combatida durante

\footnotetext{
2 Martínez, R. (10 de diciembre de 2018). El Papa: 'Llamados a respetar los derechos fundamentales de cada persona'. Vatican news. https://www.vaticannews.va/es/papa/news/2018-12/papa-francisco-mensaje-derechosfundamentales-declaracion-ddhh.html
} 
mucho tiempo. En efecto, el especialista europeo opta por una periodización que incluye como punto de partida el proceso revolucionario iniciado en la Francia dieciochesca. Con ello reconoce que los derechos humanos devinieron un asunto crucial para la configuración de la Iglesia desde el momento mismo de su formulación, al derruir los cimientos de una estructura social concebida desde la institución eclesiástica.

De manera complementaria, Menozzi apuesta por una mirada transnacional. Descartada la óptica institucionalista, centra la atención en dos aspectos: por un lado, estudia la posición del papado, dada su centralidad en una estructura monárquica que atravesó un proceso de "romanización" durante una fase del período considerado; por otro, indaga en aquellos círculos de la cultura católica, dentro y fuera de Europa, que manifestaron públicamente interés en tratar la cuestión de los derechos humanos. Tal opción le permite evaluar de manera global las redefiniciones, los debates y sus repercusiones al interior del heterogéneo y dinámico universo católico, en dos siglos en los que la Iglesia atravesó transformaciones significativas.

Para cumplir con sus objetivos, el estudioso italiano recurre a un análisis cualitativo de un corpus variopinto, integrado por documentos confesionales y no confesionales, éditos (como la colección Enchiridion delle Encicliche) e inéditos (entre ellos, la prensa escrita). El resultado es una obra estructurada en seis capítulos que reconstruye el desarrollo de la postura católica frente a una organización de la vida colectiva sustentada en la atribución que tienen las personas, sin distinción alguna, de derechos fundamentales. Cada una de las secciones está orientada a momentos clave en esta trayectoria.

Los capítulos iniciales están destinados al "largo siglo" XIX. En el primero de ellos, Menozzi aborda el impacto de la Declaración de 1789, entre la adhesión de la Iglesia galicana y la condena de Roma. En particular, examina cómo la tesis romana de que los "derechos del hombre" se hallaban en contraposición de los "derechos de Dios" como base de la convivencia civil logró un rápido consenso dentro de la cultura católica de 1800. En las décadas siguientes, tal como expone el autor, emergieron voces alternativas, como aquellas que vieron en la Iglesia una guardiana de los derechos del hombre, aunque difícilmente lograrían adhesiones.

Avanzada la centuria, la posición de la Iglesia no sufrió grandes modificaciones. En el segundo capítulo, analiza el impacto de la corriente neotomista -en clave antiliberal y antisocial- en la reactualización de las definiciones de la "ley natural", como fundamento de la organización de la vida colectiva e impulso en la formación de la civilización, y de la Iglesia misma, como su única intérprete. Asimismo, el italiano señala que tal formulación facilitó el acercamiento del mundo católico a la modernidad política. En este sentido, considera los alcances de la Rerum novarum (1891) y el fomento de los derechos económicos y sociales.

Las secciones posteriores comprenden la relación Iglesia y derechos humanos en el siglo XX. En ellas, el autor estudia las divergencias resultantes en lapso de entreguerras, principalmente frente a los totalitarismos y las críticas al integrismo católico (en este punto, la figura de Jacques Maritain resulta clave); la "entrada" de los derechos humanos a la cultura católica a partir de la Declaración de las Naciones Unidas; el aggiornamento de los años sesenta, en plena Guerra Fría, cuando la Iglesia adoptó una visión optimista de los derechos humanos en la realización plena de las personas; y las oscilaciones en el catolicismo post-conciliar. En conjunto, Menozzi 
evalúa cómo el mundo católico destinó enormes esfuerzos por interpretar y/o traducir la Carta de 1789, primero, y de 1948, después, bajo sus propios términos, en una búsqueda de convergencia de las dos tradiciones políticas y culturales. Finalmente, concluye con una evaluación de los pontificados de Juan Pablo II y Benedicto XVI, tiempo en el que observa una Iglesia que no logra superar la herencia de la tradición intransigente y facilita el "retorno de la ley natural".

En suma, para las lectoras y los lectores interesados en la historia del catolicismo y los derechos humanos, el trabajo de Menozzi constituye una pieza clave. En trescientas páginas, el autor italiano realiza un trabajo de síntesis riguroso, que proporciona información sobre una temática de interés en el contexto actual. Para quienes se abocan a este campo de estudios, el volumen se inserta en los debates actuales de la secularización y la modernidad religiosa en Europa y América Latina. El estudio de la posición asumida por Roma frente a la Declaración Universal de los Derechos del Hombre y el Ciudadano constituye una ventana para observar un proceso dinámico, multidimensional y complejo de reacomodamientos, en el que Estado e Iglesia, lo político y lo religioso, lo público y lo privado, estuvieron imbricados.

\section{Referencias bibliográficas}

1. Menozzi, D. (2019). Da Cristo Re alla città degli uomini. Cattolicesimo e politica nel '900. Morcelliana.

2. Menozzi, D. (2020). "Crociata". Storia di un'ideologia dalla Rivoluzione francese a Bergoglio. Carocci. 